\title{
Fayga Ostrower, uma vida aberta à sensibilidade e ao intelecto
}

\section{Fayga Ostrower, a life open to sensibility and to the intellect}

\author{
Carla Almeida \\ Centro de Estudos do \\ Museu da Vida \\ Casa de Oswaldo Cruz/Fiocruz \\ Av. Brasil 4365, Manguinhos \\ 21045-900 Rio de Janeiro - RJ - \\ Brasil \\ carlalmeida@coc.fiocruz.br
}

\begin{abstract}
ALMEIDA, C.: Fayga Ostrower, uma vida aberta à sensibilidade e ao intelecto.

História, Ciências, Saúde-Manguinhos, v. 13, (suplemento), p. 269-89, outubro 2006.

Este texto discute a contribuição da artista plástica, educadora e humanista Fayga Ostrower (1920-2001) ao tema ciência e arte. Fayga dedicou sua vida às artes plásticas e à educação artística. Entre 1948 e 2001, expôs suas obras em diversos museus brasileiros e estrangeiros. Lecionou durante 16 anos no Museu de Arte Moderna do Rio de Janeiro, ministrou cursos nas principais instituições artísticas do país e proferiu palestras - para estudantes, artistas, operários e empresários - por todo o mundo, com carisma, didatismo e clareza. Além de uma breve biografia da artista, pretende-se apresentar aqui suas principais idéias sobre as relações entre a arte e a ciência, um tema que a fascinava. Muitas dessas reflexões foram registradas por ela em seu penúltimo livro, A sensibilidade do intelecto: visões paralelas de espaço e tempo na arte e na ciência, pelo qual recebeu o Prêmio Literário Jabuti, da Câmara Brasileira do Livro, em 1999.
\end{abstract}

PALAVRAS-CHAVE: arte; ciência; arte e ciência.

ALMEIDA, C.: Fayga Ostrower, a life open to sensibility and to the intellect.

História, Ciências, Saúde-Manguinhos,

v. 13, (supplement), p. 269-89, October 2006.

The article discusses Fayga Ostrower's contribution to both science and art. Artist, educator, and humanist, Ostrower (1920-2001) devoted her life to art and art education. Between 1948 and 2001, her works were exhibited at numerous museums in Brazil and internationally. She taught at Rio de Janeiro's Museu de Arte Moderna for sixteen years, gave classes at Brazil's top art institutes, and lectured with charisma, enlightenment, and clarity to students, artists, workers, and businessmen around the world. The article offers a brief biography of the artist's life, and describes her main ideas on the relation between art and science, a topic that fascinated her. Many of these thoughts were recorded in her penultimate book, A sensibilidade do intelecto: visões paralelas de espaço e tempo na arte e na ciência (The sensibility of the intellect: parallel views of space and time in art and science), for which she received Brazil's top literary prize, the Jabuti, in 1999.

KEYWORDS: art; science; art and science. 
U ma gravura de Goya, uma reprodução de Vermeer e uma foto de Einstein. Estas imagens faziam companhia à artista plástica e educadora Fayga Ostrower em seu último ateliê, na avenida Rui Barbosa, com vista privilegiada para o Pão de Açúcar. Nesse espaço, Fayga produziu parte de sua obra artística, dividida basicamente em gravuras - nas mais variadas técnicas -, aquarelas e desenhos. Ali, concebeu, aprofundou e amadureceu muitas de suas idéias sobre arte, literatura, história, filosofia e ciência.

O seu ambiente de trabalho, assim como toda a sua casa, era marcado pela simplicidade: móveis modestos, aparelhos eletrônicos básicos (televisão, rádio e videocassete), vídeos importantes para o seu trabalho e livros, muitos livros. Além da simplicidade, a determinação e generosidade foram traços importantes de sua personalidade e de sua trajetória profissional.

A diversidade temática de seus livros, cursos, palestras e conversas que fomentava no seu círculo de amizades marcavam o caráter questionador de Fayga em sua busca por uma melhor compreensão do mundo.

Em um primeiro momento, pretendemos traçar, de maneira compacta, a trajetória profissional da artista e educadora, dando ênfase à personalidade, às idéias e convicções que a acompanharam ao longo da vida e fizeram dela uma importante referência tanto no meio artístico como no meio intelectual brasileiro.

Em seguida, abordaremos algumas das principais reflexões de Fayga sobre as convergências e divergências entre os pensamentos artístico e científico, uma temática recorrente em seus livros, cursos, palestras e conversas. Grande parte dessas idéias está registrada no livro A sensibilidade do intelecto, lançado em 1998 e vencedor do Prêmio Literário Jabuti, da Câmara Brasileira do Livro, de 1999.

\section{Nasce uma artista}

Fayga Perla Krakowski nasceu em 14 de setembro de 1920 na cidade de Lodz, na Polônia, mas foi em Wuppertal, na Alemanha, que cresceu ao lado dos pais e dos três irmãos. Na condição de emigrantes judeus e diante da iminência da guerra, deixaram clandestinamente o país em 1933. Viveram quase um ano na Bélgica até se transferirem para a América Latina, uma das únicas opções para os refugiados da Segunda Guerra Mundial. O Brasil foi o destino escolhido pela família.

Durante a viagem de navio para o Brasil, Fayga aproveitava para desenhar, já demonstrando boa habilidade artística. Pelos desenhos que fazia, ganhava chocolate do capitão da embarcação uma semana após seu falecimento, em 2001, a família encontrou o caderno no qual estavam esses desenhos. Em depoimento na cerimônia de recebimento do título de Cidadã Honorária do Rio de 
Janeiro, concedido a Fayga em 1985, seu irmão, David Krakowski, recordou a viagem, os desenhos e os chocolates:

A sua primeira manifestação artística da qual eu me recordo dáse no cargueiro que nos trouxe ao Brasil. Espontaneamente pega um caderno e retrata inicialmente os recantos do navio. Os seus desenhos chamam a atenção da tripulação, a qual ela passa também a retratar, desde os oficiais até o capitão. Pouco posso falar do valor desses desenhos, pois ainda era muito criança, mas o que eu apreciava mesmo era o chocolate que ela ganhava com seus desenhos e que dividia com os irmãos. (Krakowski , 2001, p. 179)

Tinha 13 anos quando chegou ao Brasil, e logo começou a trabalhar para ajudar a sustentar a família. $O$ fato de falar fluentemente três línguas - alemão, francês e inglês -, além de português, ajudou-a a encontrar logo um emprego (como secretária em um escritório) e a crescer rapidamente na 'carreira de executiva'. Aos 24 anos, era secretária-executiva do presidente da General Electric.

Nesse meio tempo, inscreveu-se na Associação de Belas Artes freqüentava as sessões de desenho da entidade - e conheceu Heinz Ostrower, com quem se casou em 1941.

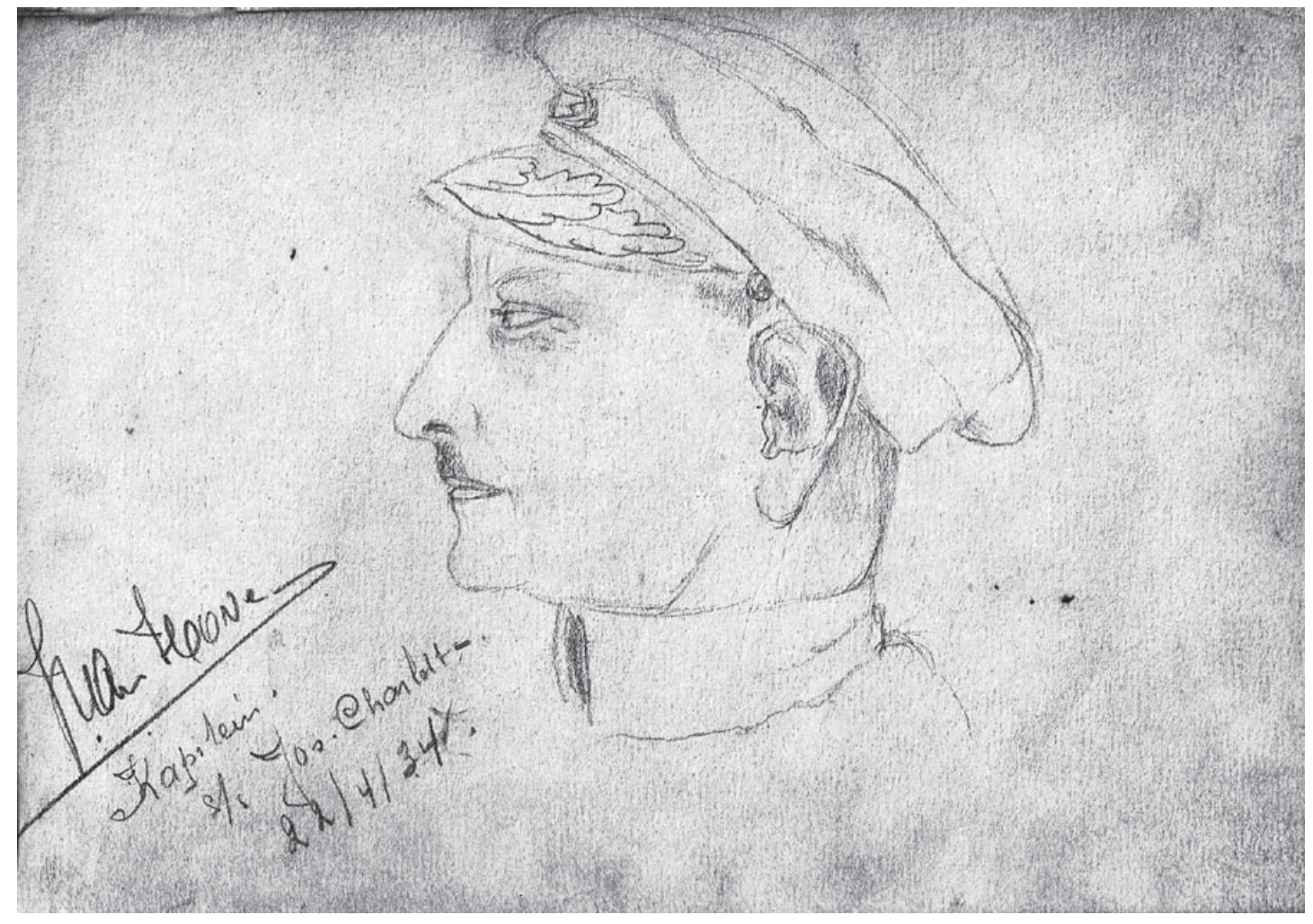

Caderno de desenho de Fayga traz este esboço inédito do capitão do navio que trouxe a família Krakowski ao Brasil em 1934. 
${ }^{1}$ Essa declaração foi feita por Fayga no programa de televisão "Ciência e arte: tudo a ver", veiculado pelo canal da Multirio em 1998.
Em 1947, um anúncio no Correio da Manhã chamou sua atenção. Era sobre um curso de artes gráficas, de seis meses de duração, oferecido pela Fundação Getúlio Vargas. Com aulas diárias das 9 às 17 horas, seria impossível conciliá-lo com seu trabalho na multinacional. Decidiu então abandonar o posto na empresa e se inscrever no curso. Mais tarde, ela diria: “Esta decisão foi um presente que a vida me deu". ${ }^{1}$

No curso da Fundação Getúlio Vargas, dirigido pelo pintor, ilustrador, gravador, cenógrafo e crítico de arte Tomás Santa Rosa (1909-1956), teve aulas com o gravador austríaco Axl Leskoschek (1889-1975), com a professora de história da arte Anna Levy e com o pintor Carlos Oswald (1882-1971). Segundo Fayga, essas aulas mudaram totalmente o rumo de sua vida: "Assim que terminei o curso, resolvi que nunca mais em minha vida poria os pés em um escritório. Nada daquele mundo me interessava. Queria e ia ser artista" (Sampaio, 2001, p. 163).

A vida também lhe deu de presente dois filhos: Carl Robert, nascido em 1949, e Anna Leonor (Noni), em 1952 - um ano após naturalizar-se brasileira.

\section{Gravando o nome na história}

Com um par de goivas (instrumentos utilizados na xilogravura) que ganhara de uma colega de trabalho quando ainda trabalhava na multinacional e com um pedaço de linóleo que comprou, Fayga improvisou uma prensa e começou a gravar. Seus primeiros trabalhos profissionais foram ilustrações para livros e jornais. Entre os livros, ilustrou o romance naturalista O cortiço, de Aluísio de Azevedo.

$\mathrm{Na}$ fase inicial de sua carreira, dedicou-se à gravura figurativa, de caráter crítico, buscando retratar em suas obras os sentimentos, os costumes e a miséria do povo brasileiro. Com traços expressio-nistas - caracterizados pela abordagem exaltada e por uma visão enfática -, revelava sua revolta perante as injustiças sociais (ver p. 276).

Em 1948, realizou sua primeira exposição, nos pilotis do Ministério de Educação e Cultura, no Rio de Janeiro; uma das únicas da fase figurativa, que teve curtíssima duração.

Diversos questionamentos - principalmente quanto à expressividade de suas composições figurativas - começaram a surgir da cabeça e das mãos de Fayga, levando-a a buscar uma nova forma de representar seus sentimentos e suas experiências. Certa vez ela relatou o que sentiu nessa fase: "Percebi que em certas situações humanas, de grande sofrimento, guerra, bomba atômica, campo de concentração, fome, qualquer comentário artístico que queira dar dimensões estéticas ao fato torna-se sem sentido" (Ostrower, 1983). 
Foi nesse momento de dúvida e angústia que Fayga tomou conhecimento, através de livros, da obra de Cézanne (1839-1906). O artista provocou grande fascínio em Fayga, que afirmou: "Sua visão de espaço e a problemática da forma que levanta foram uma revelação tão grande para mim, que tudo o que até então imaginava se transformou" (Ostrower, 1983).

A busca por uma maneira mais densa de se expressar e a influência de Cézanne desencadearam um processo de transformação em sua obra. Aos poucos, foi deixando a arte figurativa e caminhando rumo à abstração (ver p. 278). Essa mudança de estilo foi, na época, fortemente rechaçada pelos críticos de arte e por seus colegas. Mas Fayga não voltou atrás em sua decisão.

Em 1954, ano muito importante para a artista, realizou sua primeira exposição individual abstrata e começou a dar aulas de teoria da arte no Museu de Arte Moderna do Rio - marco inicial de sua trajetória como educadora.

Daquele ano em diante, a carreira da artista deslanchou. Em 1955, recebeu uma bolsa para estudar arte em Nova York, onde passou um ano. Em 1957, recebeu o Prêmio Nacional de Gravura na IV Bienal de São Paulo. E, em 1958, veio o reconhecimento internacional: foi laureada com o Prêmio de Gravura da Bienal de Veneza. Segundo o crítico de arte Wilson Coutinho (2001, p. 33), a premiação era extremamente valiosa na época e teve grande repercussão no país, elevando o status da gravura brasileira ao da pintura e da escultura. Cursos foram abertos e uma geração inteira dedicouse à gravura, tornando-a um dos pilares do modernismo brasileiro.

Essas premiações, embora importantes, mudaram pouco o cotidiano de Fayga, segundo ela própria afirmou: "Os grandes problemas, os problemas íntimos ao trabalhar, permaneciam inalterados. As matrizes e as folhas de papel continuavam olhando para mim como quem dizia: e agora? E eu tinha sempre o mesmo medo de começar um novo trabalho" (Ostrower, 1983).

O ano de 1965 foi difícil. Por motivos de saúde, viu-se impossibilitada de trabalhar, o que, para Fayga, era a maior tortura a que poderia ser submetida. Apesar de todo o sofrimento, esse período foi importante para os passos seguintes de sua carreira. Com a recuperação, surgiu uma nova faceta em suas obras, como relatou (ver cópia de xilogravura à p. 277):

Quando finalmente tornei a trabalhar, constatei, perplexa, que algo de fundamental devia ter mudado em mim: não só eu estava usando cores intensas, luminosas, como também a própria cor tinha se tornado, ela mesma, forma expressiva; em vez de acompanhar e sustentar certos elementos visuais na estrutura do espaço, a cor agora era o elemento predominante em minha imagem. (Ostrower, 1983) 
2 Noni Ostrower, filha de Fayga, concedeu uma série de entrevistas a Carla Almeida (entre novembro de 2005 e fevereiro de 2006) para a realização deste artigo. Também disponibilizou gentilmente a maior parte do material de pesquisa utilizado.
3 Programa de televisão "Ciência e arte: tudo a ver", veiculado pelo canal da Multirio em 1998.

\section{${ }^{4}$ Luiz Alberto}

Oliveira, físico nuclear e cosmólogo do Centro Brasileiro de Pesquisas Físicas CBPF, concedeu entrevista a Carla Almeida, em 19.01.2006, especialmente para este artigo. Ele foi amigo de Fayga e participou do grupo formado pela artista para discutir o livro A sensibilidade do intelecto.
Não foi a primeira nem a última vez que novos elementos surgiram em suas composições. Fayga deixava-se levar ao mesmo tempo pelo consciente e pelo inconsciente, ou, como preferia denominar, pelo intelecto e pela sensibilidade. Esse era, para ela, o caminho real da imaginação e da criação.

Embora a principal parte de sua obra tenha se concentrado na produção de gravuras (xilogravuras, gravuras em metal, litografias e serigrafias), desenhos e aquarelas, Fayga experimentou outras técnicas - como a concepção de grandes murais, a esmaltação de metais, o desenho de jóias, a criação de cartazes, capas, ilustrações de livros e discos e a padronagem de tecidos. A esta última dedicou 15 anos, contabilizando cerca de quatrocentos padrões diferentes, alguns dos quais usava para decorar a casa (ver um deles à p.290).

Entre 1980 e 1990, fez muitos trabalhos em litogravura e aquarela, marcados especialmente pelo lirismo, luz e ritmo. Essas características ficaram ainda mais evidentes nas últimas aquarelas produzidas pela artista, exibidas em 1999 na exposição "A Música da Aquarela", no Museu Nacional de Belas Artes. Após percorrer várias cidades no Brasil, a exposição foi para a Europa, itinerando por Paris, Berlim, Roma e Lisboa (ilustração 7).

Em 13 de setembro de 2001, Fayga morreu de câncer, no Rio de Janeiro. Foi certamente pega de surpresa, pois, como conta sua filha Noni Ostrower, ${ }^{2}$ tinha uma agenda cheia de compromissos para 2002.

\section{Arte: patrimônio da humanidade}

Fayga defendia que a arte era uma linguagem universal e vital para o homem. Lamentava muito o fato de se ter tornado uma manifestação elitista e um objeto considerado de luxo. Dizia ela: "Todos buscam a beleza, a harmonia; esta busca não depende da classe social". ${ }^{3}$

A beleza a que Fayga sempre se referia não designava simplesmente o 'bonitinho' - como costumava dizer pejorativamente. Ela falava da 'beleza essencial', da 'beleza como verdade interior da forma, uma ordenação, onde todos os componentes e todos os relacionamentos formais entre eles se apresentam necessários e plenamente significativos" (Ostrower, 1998, p. 286). Era dessa beleza, acreditava ela, que a humanidade necessitava, e, como educadora, procurou torná-la acessível a um público bastante diversificado.

Amigo da artista, o físico Luiz Alberto Oliveira afirma: "Para Fayga, todas as pessoas tinham o direito a uma formação que lhes possibilitasse apreciar e produzir os frutos do conhecimento humano. Isso sempre norteou a Fayga, enquanto educadora, criadora, escritora e pensadora". ${ }^{4}$ 


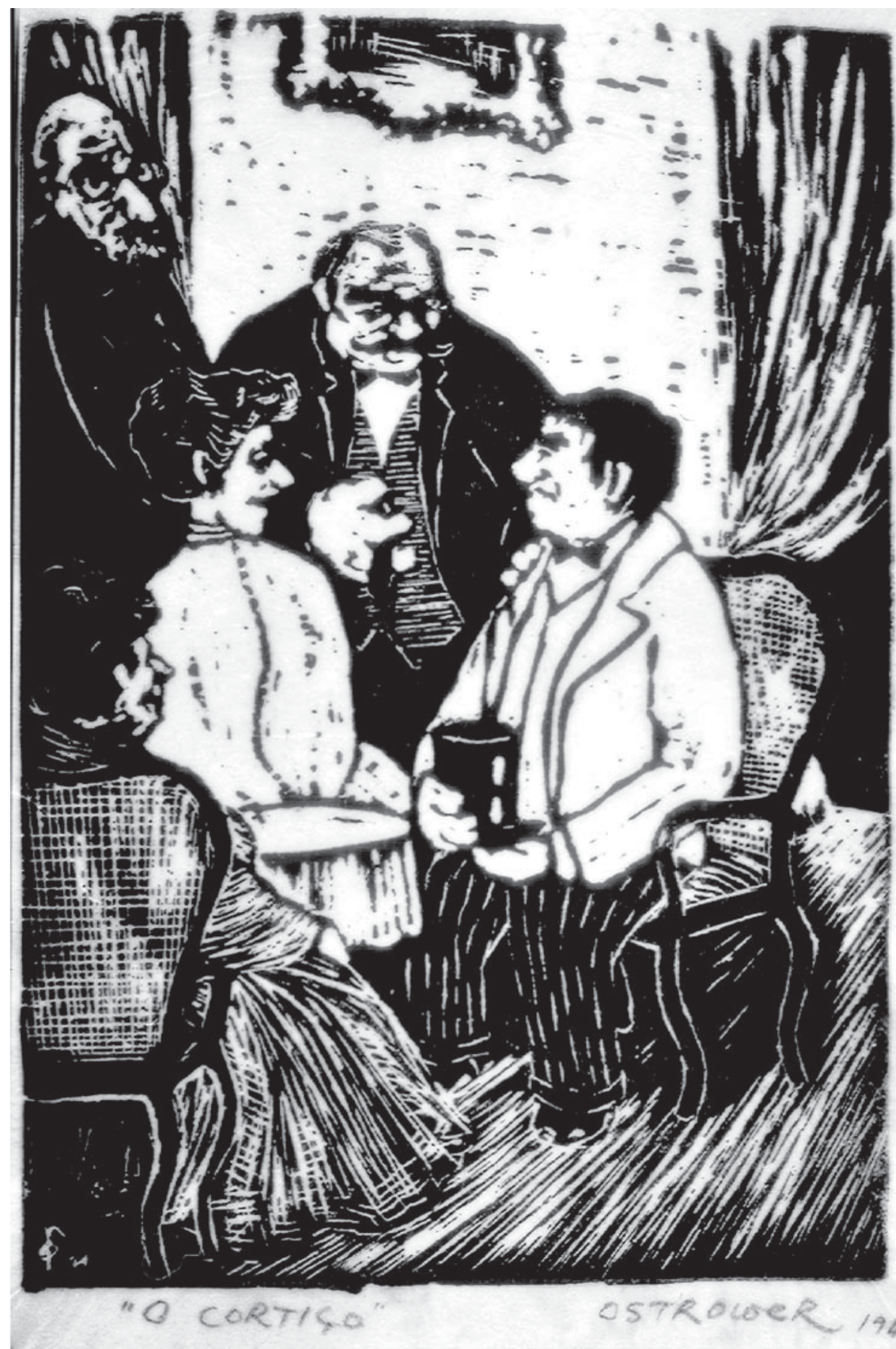

Gravura em linóleo, em preto sobre papel de arroz, para o livro O cortiço, de Aluísio Azevedo. 


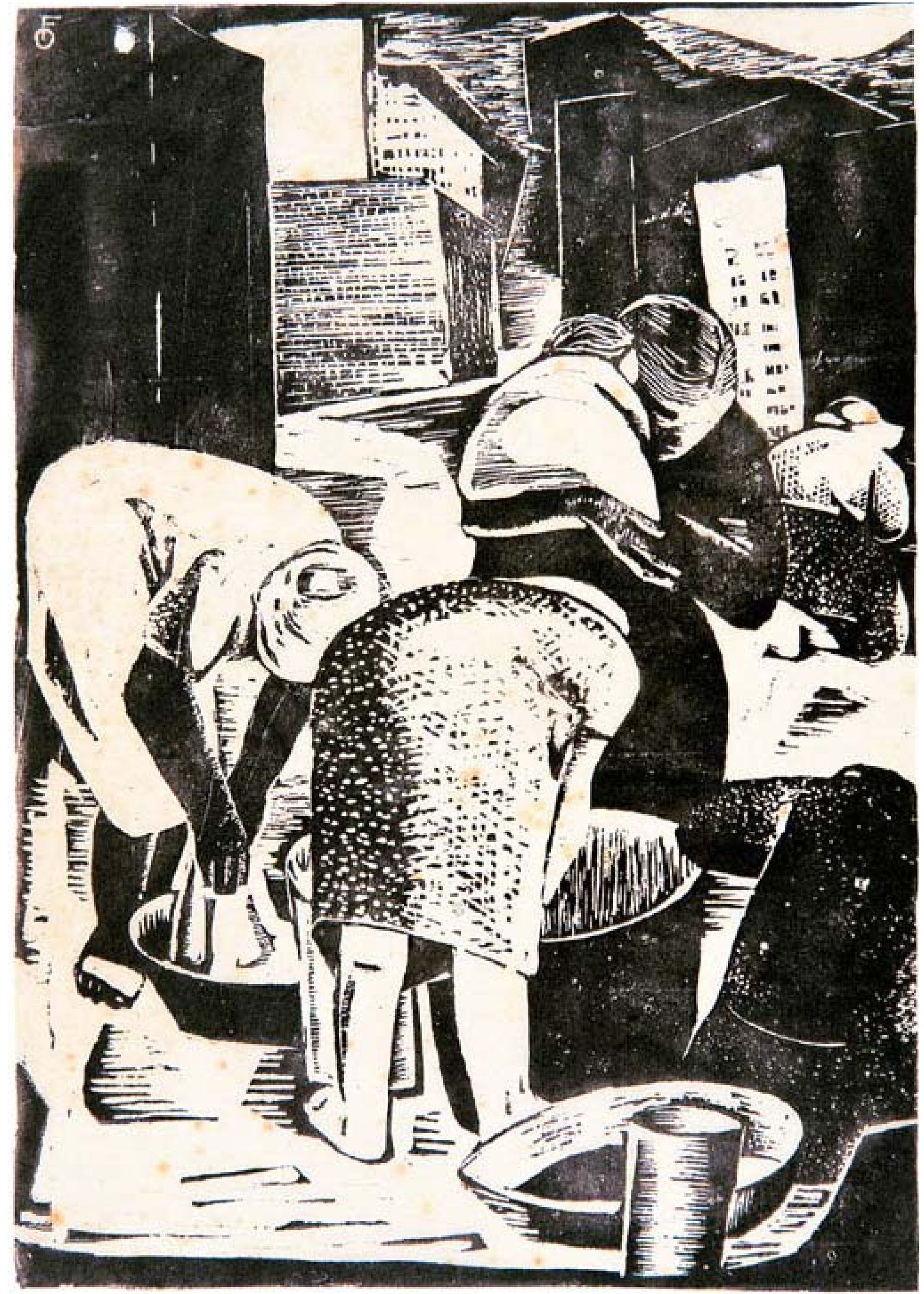

Lavadeiras. Água-forte e ponta-seca em preto, sobre papel Rives, 20x16 cm, 1950. 


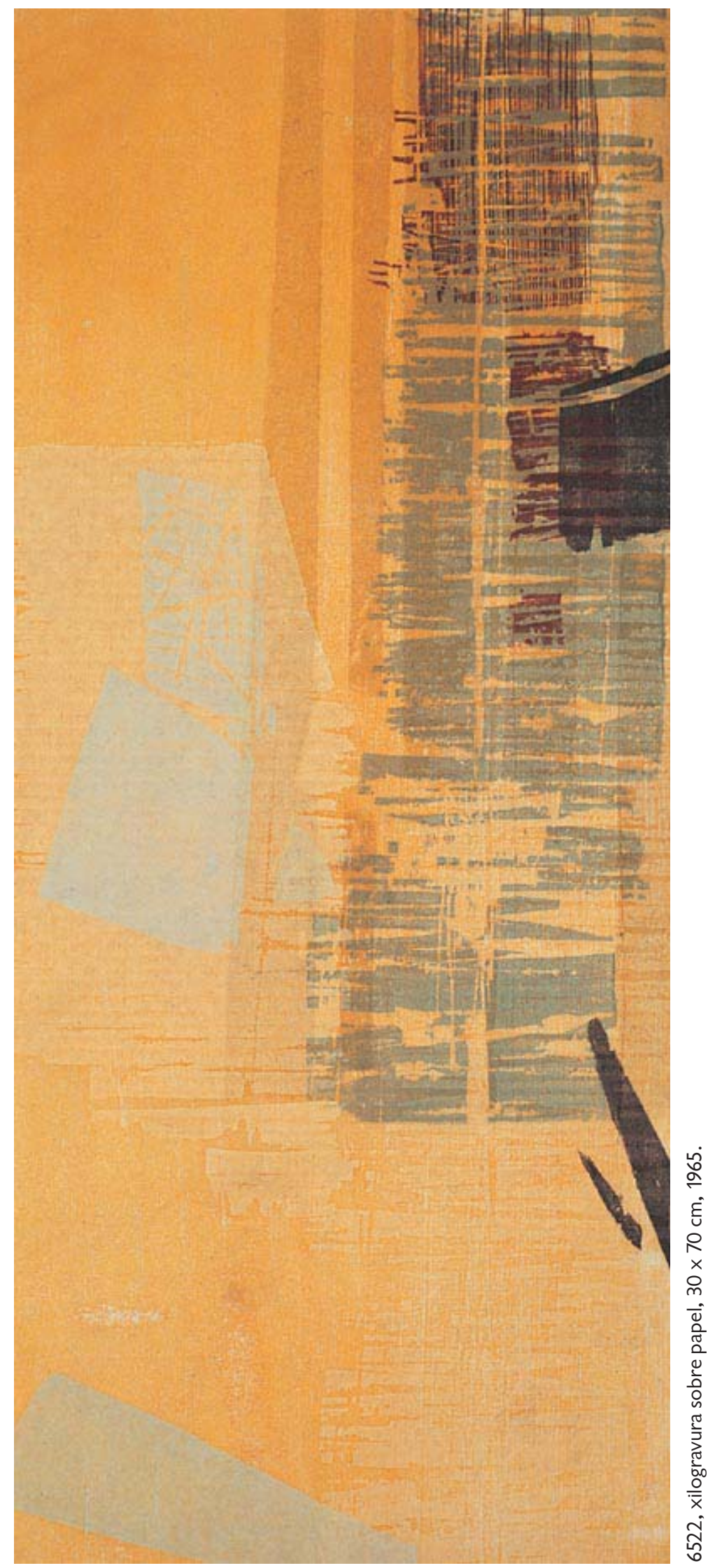




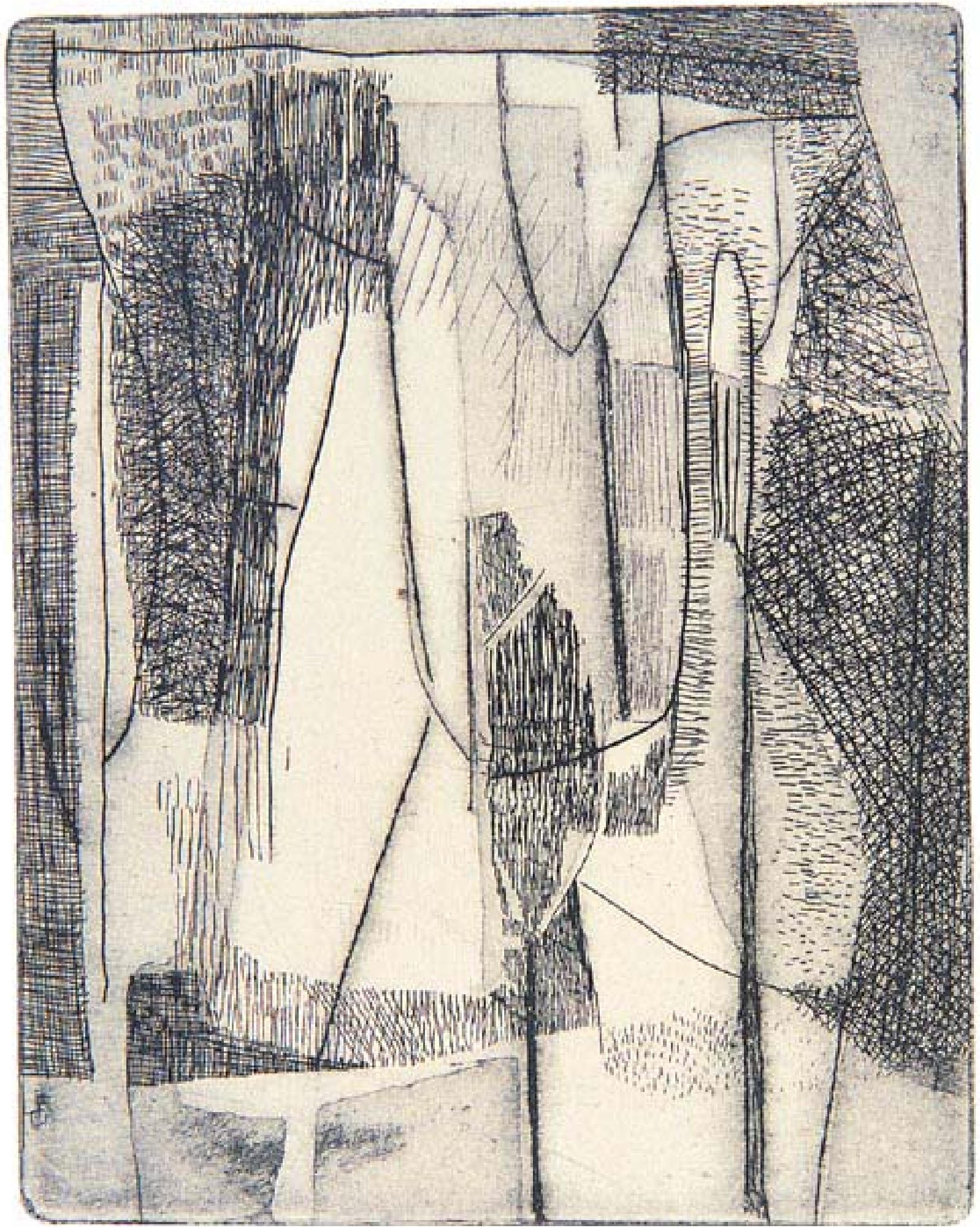

Floresta, água-forte sobre papel, 12,3 × 9,7 cm, 1952 . 
Nesse sentido, Fayga contribuiu para a divulgação e o ensino da arte no Brasil. Durante 16 anos (1954-1970) ministrou cursos teóricos no Museu de Arte Moderna do Rio de Janeiro e, ao longo de toda a vida, outros tantos em diversas instituições de ensino: Escola de Belas Artes, Centro Brasileiro de Estudos Internacionais, Escola de Arquitetura da Universidade Federal de Minas Gerais, Instituto de Arte da Universidade Federal do Rio Grande do Sul, Escolinha de Arte do Brasil (da Funarte), Centro de Artes da Universidade Federal do Espírito Santo, Centro de Arte Contemporânea

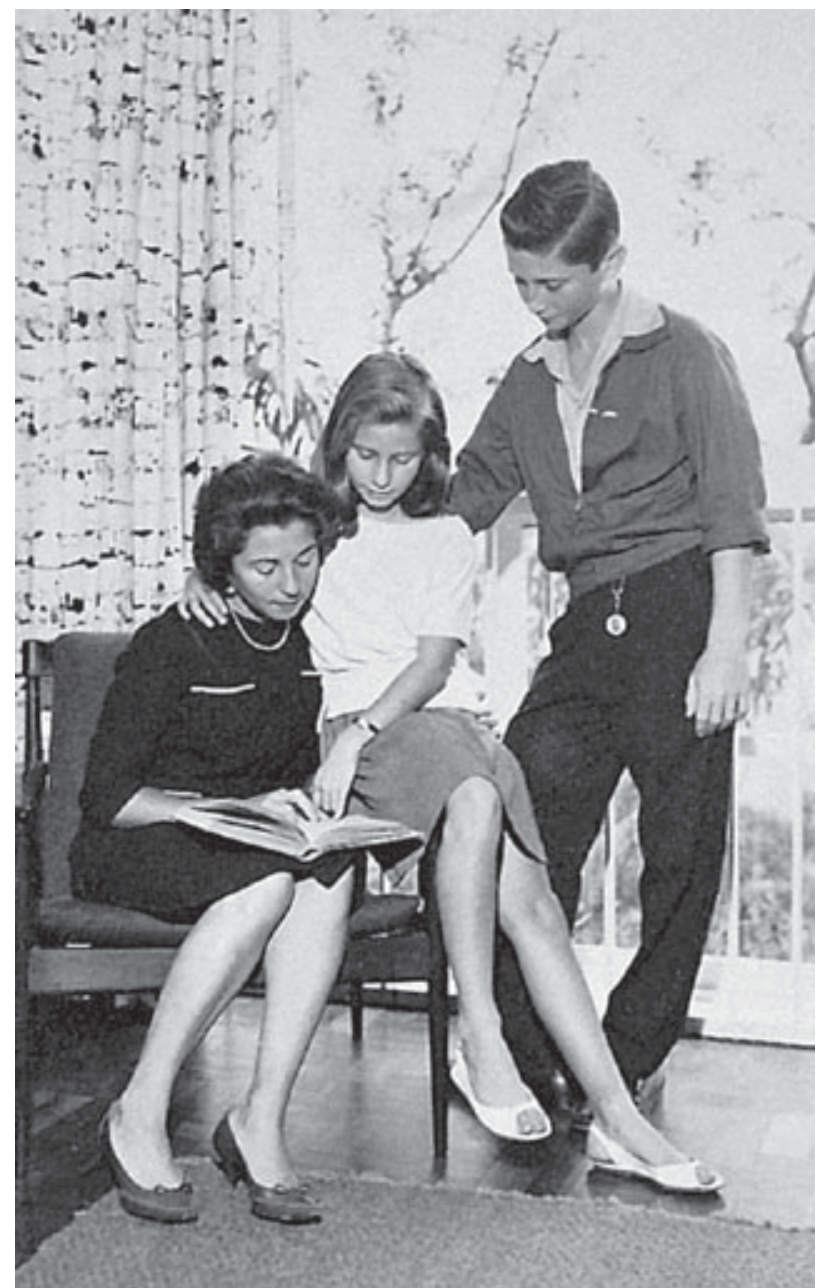

Fayga com os filhos Carl Robert e Anna Leonor (Noni); no fundo um dos padrões que criou para tecidos (1963) 
5 Criatividade $e$ processos de criação. Rio de Janeiro: Vozes, 1977; Universos da arte. Rio de Janeiro: Campus, 1983; Acasos e criação artística. Rio de Janeiro: Campus, 1990; Goya, artista revolucionário e humanista. São Paulo: Imaginário, 1997; $A$ sensibilidade do intelecto. Rio de Janeiro: Campus, 1998; A grandeza humana: cinco séculos, cinco gênios da arte. Rio de Janeiro: Campus, 2003.

6 Entrevista concedida a Carla Almeida. (da Funarte) e Fundação Bienal de São Paulo, entre outras entidades nacionais e internacionais.

Além do circuito acadêmico - que também incluía aulas para estudantes de psicologia, filosofia e matemática -, Fayga ministrou cursos sobre arte para operários, empresários e o público geral. Falar para esse público não especializado era, para ela, um grande desafio e, ao mesmo tempo, prova de que a arte era amplamente acessível e podia ser apreciada por qualquer pessoa.

Os seis livros ${ }^{5}$ de sua autoria também refletem esse esforço de popularização da arte. Todos eles abordam questões complexas do universo artístico e da natureza humana, de forma clara e acessível. Fayga os dedicava a todas as pessoas que, assim como ela, amavam a arte e a vida.

Noni Ostrower, filha da artista, afirma: "Minha mãe tinha uma maneira muito simples de falar sobre problemas complexos. Para ela, a simplificação era um equívoco, seria como subestimar a inteligência das pessoas, porque todo mundo que vive a complexidade da vida também pode entender a complexidade da arte". ${ }^{6}$

Fayga esteve à frente de cargos culturais importantes, nos quais buscava angariar mais atenção para a arte. Entre 1963 e 1966, foi presidente da Associação Brasileira de Artes Plásticas. De 1978 a 1982, presidiu a comissão brasileira da International Society of Education through Art - Insea, da Unesco. E, de 1982 a 1988, fez parte do Conselho Estadual de Cultura do Rio de Janeiro.

Como reconhecimento por sua dedicação e contribuição à cultura brasileira, foi agraciada com a Ordem do Rio Branco em 1972, recebeu o título de Cidadã Honorária do Rio de Janeiro em 1985,

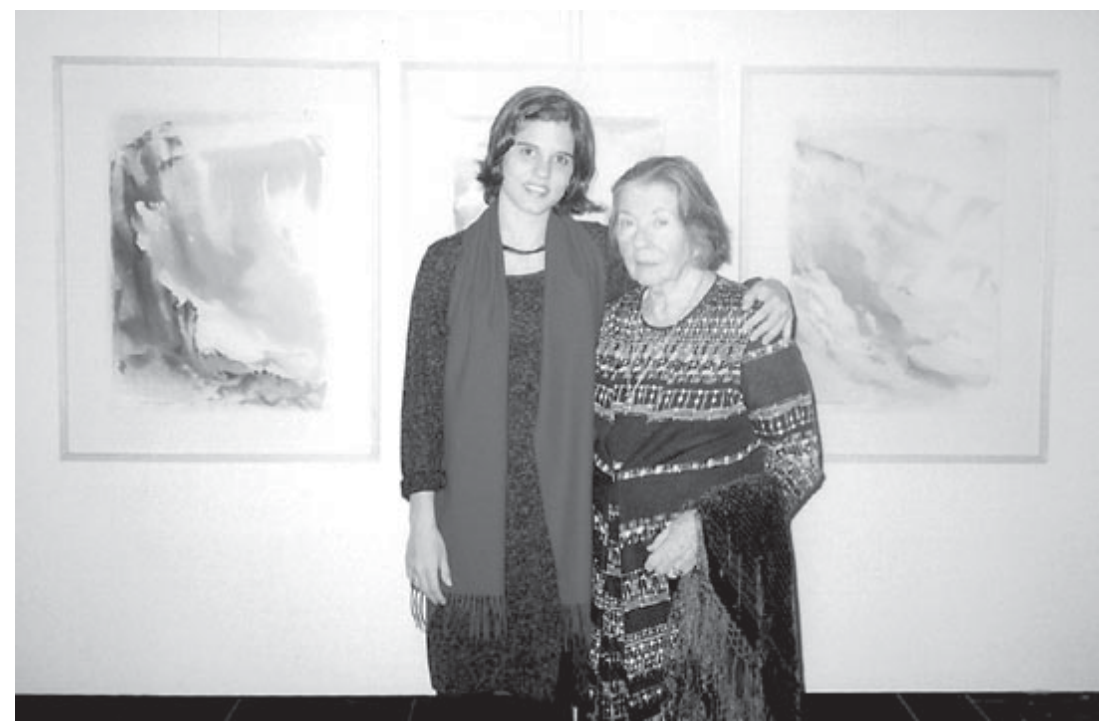

Fayga e a neta Letícia Ostrower na exposição "A Música da Aquarela” (Berlim, fevereiro de 2001). 
foi condecorada com o Prêmio do Mérito Cultural pelo presidente da República do Brasil em 1998 e, em 1999, conquistou o Grande Prêmio de Artes Plásticas do Ministério da Cultura.

Para o poeta e crítico de arte Ferreira Gullar, Fayga se destacava não só como artista, mas também como pensadora:

Podemos falar de Fayga como uma personalidade única e que, ao longo de sua vida, tanto no trabalho de criação quanto no campo da reflexão, reuniu uma soma de conhecimento artístico e humano que não encontro em qualquer outro artista brasileiro. Desconheço a existência, entre nós, de alguém igualmente equipado para o exercício do trabalho de arte e a transmissão de seu conhecimento. (CCBB, 1995, p. 9)

\section{Arte e ciência, sensibilidade e intelecto}

Um dos maiores empreendimentos de Fayga como intelectual foi reunir capacidades, compartilhar pensamentos e abrir espaço para um centro de reflexão em torno de si. Ela costumava estimular a conversa entre os amigos e fomentar discussões sobre temas diversos: arte, é claro, mas também literatura, história, filosofia, música, cinema, ciência...

Ao escrever um livro, por exemplo, gostava de discutir com os colegas as idéias que propunha expor. Ela reunia todo o conteúdo a ser abordado, formava um grupo de amigos ligados a áreas diferentes do conhecimento e marcava reuniões semanais em sua casa para discutir detalhadamente as idéias do livro. A intenção era torná-las claras ao público não-especializado, sem prejuízo da densidade e complexidade do conteúdo em discussão. Além disso, interessava-se em compreender as convergências e divergências entre o modo de pensar na arte e o modo de pensar em outras vias do conhecimento, por isso sempre buscava a maior diversidade possível de pontos de vista.

Foi com esses objetivos que formou um grupo de discussão em 1997, quando se preparava para escrever seu quinto livro - A sensibilidade do intelecto -, sobre os paralelos existentes entre o modo de pensar na arte e na ciência. Durante um ano, o grupo - integrado por Lilia Sampaio, pintora e professora de educação artística; Luiz Alberto Oliveira, físico; Roberto Santoro de Almeida, psiquiatra e musicólogo; Isabel Gurgel Valente, psicanalista, e Gilda Salem Szklo, professora de literatura brasileira e francesa - discutiu o conteúdo do livro, publicado em 1998 (ver foto à p. 282).

A seguir, apresentaremos algumas das reflexões de Fayga sobre arte e ciência, um tema que sempre a fascinou. Muitas delas estão presentes no livro $A$ sensibilidade do intelecto. Outras foram recolhidas de seus demais livros, entrevistas, textos e outras fontes (detalhadas no item "Referências bibliográficas"). Embora Fayga não 
esteja mais entre nós, optamos por usar o presente, pois consideramos que seus pensamentos continuam e continuarão vivos.

\section{Momentos históricos convergentes e práticas divergentes}

As correspondências entre os pensamentos artísticos e científicos são, para Fayga, evidentes e significativas, tanto nas perguntas feitas sobre a vida e o mundo, quanto nas respostas encontradas e manifestadas por elas em determinados momentos históricos. Em A sensibilidade do intelecto, ela destaca e analisa três deles: o Renascimento, os anos pós-Revolução Francesa e o início do século $\mathrm{XX}$, todos períodos de grandes transformações culturais.

No Renascimento, afirma, o ideal do humanismo - que tirou Deus e colocou o homem no centro do mundo - abriu espaço para o surgimento de uma nova forma de representação do espaço.

$\mathrm{Na}$ arte, relata Fayga, os objetos passaram a ser retratados da maneira como eram vistos pelo olho humano, ou seja, em três dimensões. Esse novo esquema de "representação verdadeira", batizado de Perspectiva, foi rapidamente difundido e adotado pelos artistas, acarretando mudanças profundas em toda a cultura renascentista.

No campo científico, essa nova visão de mundo, diz a artista, também levou a novos questionamentos. Para responder a eles, os cientistas foram em busca de novos métodos, baseados em observações, comparações e medições dos fenômenos da natureza, dando

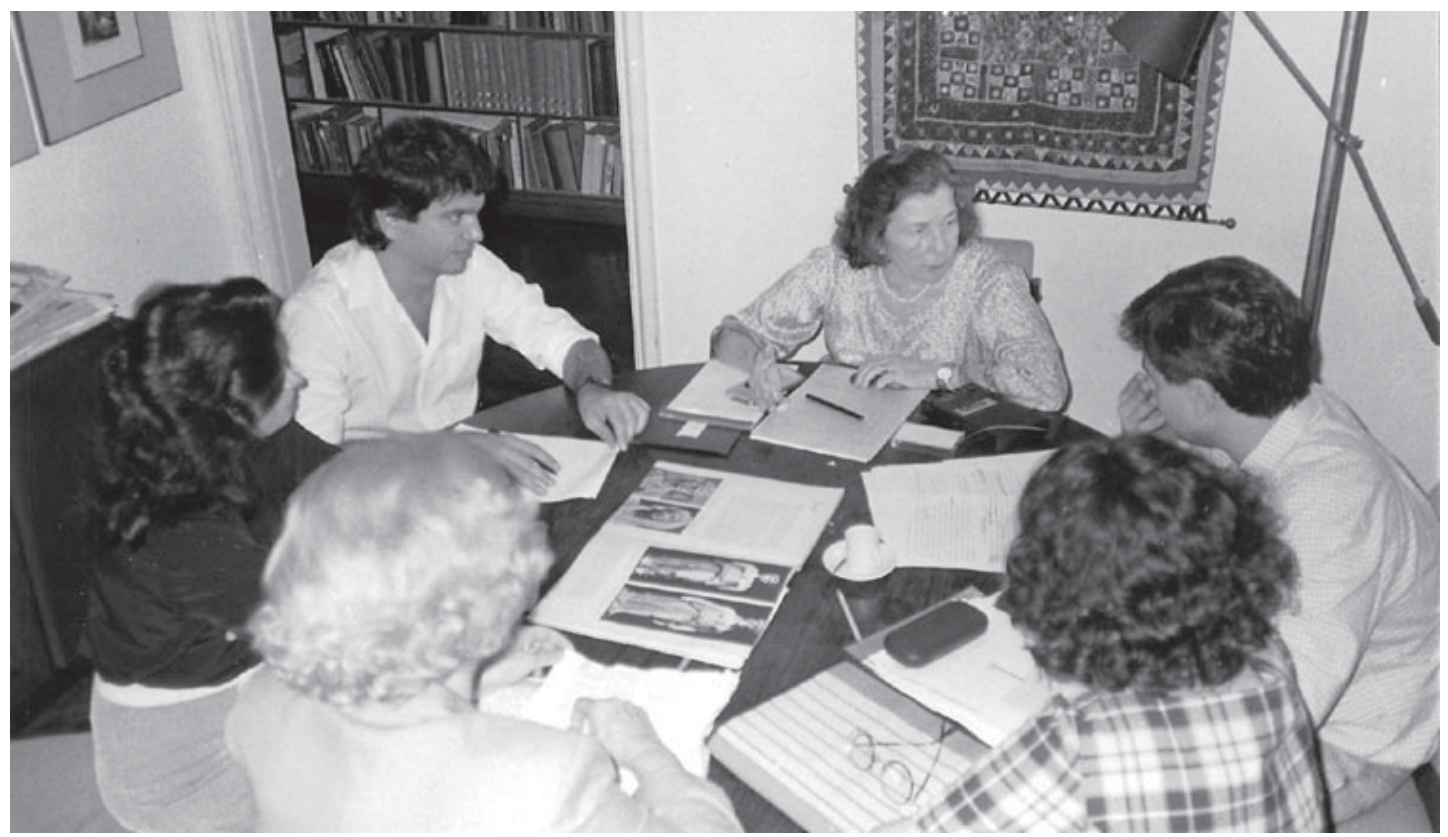

Ilustração 8 - Grupo de trabalho do livro Sensibilidade do intelecto. 
início a uma nova era do conhecimento, conhecida como Revolução Científica.

Fayga mostra no livro que tanto os novos conceitos na arte influenciavam o campo científico, a exemplo do que ocorreu com Galileu Galilei (1564-1642), quanto os novos procedimentos na ciência influenciavam o campo artístico, a exemplo de Leonardo da Vinci (1452-1516) e Piero della Francesca (1420-1492).

Segundo a artista, a partir da premissa de um mundo material observável, correspondências significativas estabeleceram-se entre os princípios da perspectiva, que ordenavam a configuração espacial nas imagens, e as noções de espaço, tempo e movimento com que Galileu Galilei revolucionaria as concepções vigentes em sua época (Ostrower, 1998, p. 286). Além de sustentar a teoria heliocêntrica formulada por Nicolau Copérnico (1473-1543), Galileu defendia que o conhecimento da realidade deveria basear-se na rigorosa observação dos fenômenos da natureza. Embora duramente atacado e perseguido pela Igreja - foi condenado pela Inquisição à prisão domiciliar e proibido de publicar suas pesquisas -, seus conceitos e métodos propagaram-se e, ampliados por outros cientistas importantes, tornaram-se o paradigma da pesquisa por quase três séculos.

Leonardo da Vinci e Piero della Francesca, por sua vez, dois artistas renascentistas, tinham visão e atitude semelhantes às de cientistas, como descreve Fayga:

Ambos se caracterizaram por seu interesse e sua observação minuciosa dos fenômenos da natureza. Outrossim, tornando-se estudiosos de matemática e geografia, ambos escreveram tratados sobre as possibilidades da perspectiva, escritos estes que não só encontraram grande repercussão na época, mas também exerceram uma profunda influência sobre gerações posteriores de cientistas. (Ostrower, 1998, p. 34-5)

A Revolução Francesa, desencadeada em 1789, e, junto com ela, o sonho de uma humanidade mais digna e mais livre, também causaram, na avaliação da artista, grande impacto na arte e na ciência do século XIX, deixando para trás as marcas do Renascimento.

$\mathrm{Na}$ arte, relata, concepções inovadoras, apresentadas por uma grande diversidade de estilos, dissolveram, aos poucos, o sistema de perspectiva, até o seu completo desaparecimento. O Neoclassicismo substituiu o Barroco e abriu caminho para uma rápida sucessão de estilos: Romantismo, Realismo e Impressionismo e outras tendências de cunho expressionista. Embora carregassem traços e visões bastante distintos, todos eles manifestavam a mudança na própria visão de vida, alterando o conteúdo expressivo das obras de arte.

Na ciência, afirma Fayga, um movimento renovador começou a tomar corpo na metade do século XIX com o surgimento da nova 
noção de energia. A noção de que, mesmo sem a interação direta entre os corpos - presente no conceito newtoniano de força-, estes podiam incorporar um potencial energético, abriu caminho para o desenvolvimento da chamada 'física de campo' (sem interação direta entre os corpos).

No século XX, Fayga aponta o surgimento quase simultâneo do movimento cubista e da formulação das teorias da relatividade e da mecânica quântica como momento de grande ruptura no pensamento contemporâneo. Naquele momento estavam em xeque as maneiras clássicas de se representar o espaço e o tempo, e tanto a arte quanto a ciência buscavam formas mais adequadas de representá-los.

Concebido por Pablo Picasso, o cubismo introduziu na arte uma visão inteiramente dinâmica e relativa do espaço, como aponta Fayga:

O dinamismo de espaços em movimento fascinava os cubistas. Espaços sempre relativos, cujas formas se recriavam em relacionamentos recíprocos. Nas imagens cubistas surge uma realidade composta de fenômenos fragmentários. Os planos são fragmentados mais e mais, e desintegrados até chegarem a facetas diminutas e quase uniformes, como se fossem uma espécie de 'átomos' de matéria. (Ostrower, 1998, p. 47)

Já a teoria da relatividade de Albert Einstein e a mecânica quântica - formulada, além do próprio Einstein, por um grupo de físicos como Max Planck, Werner Heisenberg, Niels Bohr, Erwin Schrödinger, Paul Dirac, Louis de Broglie e Max Born - e os novos conceitos por elas introduzidos provocaram uma verdadeira reviravolta no pensamento científico. Fayga afirma:

Nas magnitudes do universo astronômico, espaço e tempo perdem o caráter de entidades isoladas, sendo concebidos agora em conjunto na configuração de um continuum quadridimensional de tempo-espaço. Com isto o tempo perde o seu fluxo linear e uniforme, adquirindo nesta fusão certas qualidades do espaço. Por sua vez, o próprio espaço se encontra enlaçado ao tempo, na concepção da equivalência entre massa e energia, a qual foi formulada por Einstein na famosa equação: $E=m c^{2}$. (Ostrower, 1998, p. 217)

Revelou-se também, de acordo com a artista, através da mecânica quântica, a estreita interdependência do observador e dos fenômenos por ele observados, rompendo com a idéia de que poderia existir um espectador isolado e neutro, olhando do lado de fora para algo que acontecia do lado de dentro.

Essas novas visões de espaço e tempo abriram caminho para o desenvolvimento da ciência moderna e também para o surgimento 
de novos estilos na arte moderna, principalmente para as correntes abstratas.

Se, por um lado, a arte e a ciência apresentam momentos de convergência ao longo da história, para Fayga, as divergências são claras quanto a seus objetivos, métodos e formas de funcionamento. Em $A$ sensibilidade do intelecto, ela analisa essas diferenças na prática de cada uma das atividades.

A ciência, de um lado, busca a verdade universal. Nessa busca, adota um método bem particular: ao observar os fenômenos naturais, o cientista formula hipóteses; estas devem ser testadas em condições experimentais para que sejam validadas e se tornem modelos teóricos aceitos no meio científico. Nesse processo, o cientista divide o todo em partes cada vez menores, a serem examinadas minuciosamente e em separado, quanto à sua estrutura e função. "Seria como uma dissecação anatômica, examinando, digamos, um órgão do corpo, os vários tecidos do órgão, as células dos tecidos", afirma Fayga (Ostrower, 1998, p. 284).

A arte, do outro lado, não busca a verdade absoluta, e sim a verdade concreta de cada configuração, definida e articulada pelo artista. Para encontrar a sua verdade, o artista parte de sua própria experiência de vida. No caminho, conduzido pela intuição e razão, por suas vivências e valores, vai acrescentando novos elementos à composição, diferenciando-os e reajustando-os. Ao final, tem à sua frente uma imagem que consiste na última de muitas sínteses anteriores. E, por mais que tente repetir essa composição, seguind o passo a passo as etapas de sua elaboração, nunca poderá obter o mesmo resultado. "A espontaneidade no ato de criação, as sínteses e os momentos de insight são únicos", defende a artista (Ostrower, 1998, p. 283).

Comparando os modos da arte e os modos da ciência, Fayga enxerga no método científico um racionalismo e um reducionismo que podem representar uma ameaça à imaginação e à sensibilidade dos cientistas, como alerta neste trecho:

De certo modo, o reducionismo talvez seja inevitável; afinal, ele representa um instrumento de trabalho, que tem se demonstrado extremamente bem sucedido nas pesquisas. Mas nem por isso deixa de ser reducionismo. Esta observação é feita com a esperança de que o método não se torne a meta final, absorvendo todo o acervo de imaginação e sensibilidade e a própria postura dos cientistas ante o viver, transformando-se numa visão de mundo reducionista. (Ostrower, 1998, p. 285)

\section{Criatividade: raiz comum da ciência e da arte}

Independentemente das convergências e das divergências entre arte e ciência enumeradas por Fayga, ela frisa com especial atenção 
7 Entrevista concedida a Carla Almeida em 19.01.2006. um aspecto que se manifesta de forma idêntica nessas duas vias de conhecimento: os momentos decisivos de criação.

Segundo Luiz Alberto Oliveira, ${ }^{7}$ embora distinguisse com clareza meios, modos, técnicas e objetivos inerentes à arte e inerentes à ciência, Fayga estava convencida de que havia uma raiz comum, profunda, que unia as duas - a criatividade.

"A criatividade, como potencial, e a criação, como realização do potencial, se manifestam de modo idêntico, independentemente dos rumos específicos que depois seguirão nas duas grandes vias do conhecimento", afirma Fayga (Ostrower, 1998, p. 285). Para ela, o momento criativo, tanto na arte como na ciência, é marcado pela mistura de razão e intuição, de medidas friamente calculadas e acasos.

Por mais que envolvam hipóteses, estimativas, comparações e deduções, esses momentos não podem ser considerados puramente racionais. E, por mais que sejam momentos de revelação, espasmos, de insight, não podem ser considerados totalmente inconscientes e abstratos. "São momentos de 'compreensão intuitiva' iluminados por um súbito saber, uma súbita certeza", explica a artista (Ostrower, 1998, p. 285).

Fayga defende ainda que esse processo criador também é, embora imaginativo, concreto. $\mathrm{O}$ artista, assim como o cientista, sempre parte do que já sabe para chegar a um novo conhecimento. E assim vai expandindo seu domínio sobre a linguagem e o material que utiliza, de modo que o conhecimento intelectual nunca precisa inibir a verdadeira criatividade, muito pelo contrário. "O sensível e o intelectual reforçando-se mutuamente, a sensibilidade abrindo caminho para novos pensamentos e o pensamento estruturando as emoções", diz ela (Ostrower, 1998, p. 248).

\section{Ciência não é arte}

Uma das opiniões mais polêmicas de Fayga dentro dessa temática é a negação da ciência como arte. Embora muito interessada na interface entre essas duas atividades humanas, em seus pontos comuns e em suas distinções claras, Fayga considera um grande equívoco atribuir à ciência valor artístico. Para ela, a representação da natureza não pode ser considerada arte, pois carece de experiência humana, de sentimentos, de expressividade - para usar a linguagem artística. E é justamente nessa expressividade que está o verdadeiro valor de uma obra de arte.

Os fractais, por exemplo, formas de grande complexidade e autosimilaridade que podem ser facilmente identificadas na natureza na forma de casca de caracol, nas nuvens, nas raízes, nos flocos de neve, nas galáxias etc. -, embora belíssimos, não devem ser considerados obras de arte, como afirma Fayga: 
Ainda que suas formas nos proporcionem um grande prazer estético, tais formas se nos apresentam em termos neutros, sem conteúdos afetivos. Pois vejamos: seria possível caracterizar as imagens de fractais como sendo alegres, melancólicas, tristes, irônicas, líricas, dramáticas, trágicas? Penso que qualquer um desses atributos estaria fora de propósito. As formas simplesmente não encerram este tipo de significado. Elas carecem de expressividade. (Ostrower, 1999, p. 197)

Nesse sentido, Fayga faz algumas ressalvas à obra do artista abstrato norte-americano Jackson Pollock (1912-1956) [sobre Pollock, veja artigo de Richard Taylor nesta edição]. Influenciado pelos preceitos do surrealismo, que proclamava que a única realidade era a dos sonhos e a única ação verdadeiramente livre era a do inconsciente, ele adotou o automatismo como um método de pintar. Com essa técnica, produzia imagens caracterizadas por linhas soltas e ritmos livres, que se assemelhavam, muitas vezes, às formas fractais encontradas na natureza.

Na avaliação de Fayga, os quadros de Pollock trazem alguns problemas sérios de ordem estrutural. O excesso de contrastes, distribuídos de maneira muito uniforme no plano pictórico, o fluxo por demais solto das linhas e a falta de tensão espacial em suas composições tornam seus formatos arbitrários e suas margens totalmente dispensáveis - pois o fluxo do movimento poderia prosseguir e fazer parte de uma totalidade maior. Com isso, o plano pictórico perde sua função como estrutura espacial articulada pelo artista e como dimensionador do conteúdo expressivo criado na imagem. Isso, para ela, é uma falha bastante grave.

Assim como os fractais, as formas geométricas são, para Fayga, completamente vazias de conteúdo expressivo. Enquanto, na arte, as formas devem ser impregnadas de sensualidade, na geometria as formas prescindem de qualquer aspecto sensual ou afetivo. Portanto, embora muitos artistas utilizem formas geometrizadas em suas composições, estas só podem ser consideradas obras de arte se estiverem imbuídas de carga emocional, de experiência humana. Ela diz:

Quando olhamos para uma pintura ou quando ouvimos uma música, são as cores ou os sons que se comunicam a nós e nos comovem, e não, porventura, uma análise dos diversos comprimentos de onda ou das freqüências. Esta é a diferença fundamental entre arte e geometria, cujos termos podem ser transpostos em outros símbolos, ou mesmo em outras linguagens, sem se alterar o sentido. Mas na arte não há paráfrases. São aquelas formas, relacionadas e ordenadas naquela medida e daquele modo, e identificando aquela matéria específica, com sua específica sensualidade, que se tornam portadores de um determinado conteúdo expressivo. Geometria é geometria, não é arte. (Ostrower, 1998, p. 87) 
8 Essa é denominada 'proporção áurea' e tem um padrão totalmente diferente das outras proporções utilizadas na arte. Como explica Fayga em $A$ sensibilidade do intelecto, ela se caracteriza por não se subdividir, como acontece com as demais, por eixos verticais e

horizontais. Nem os segmentos que resultam da subdivisão são entre si

fisicamente iguais. Ao contrário, a divisão sempre produz áreas desiguais, pois em cada corte surge uma área maior e outra menor, sempre invertidas em sua direção espacial. Assim, todas as partes proporcionais são vistas a ocuparem posições assimétricas no espaço, umas diferentes das outras. Contudo, a relação global entre totalidades e partes, assim como entre as próprias partes, permanece constante: sempre a menor estará para a maior, assim como a parte maior estará para o todo. Essa proporção, já conhecida na arte egípcia, grega e assíria, foi bastante utilizada pelos artistas renascentistas, a exemplo de Leonardo da Vinci.

9 Entrevista concedida a Carla Almeida em 19.01.2006.
As pinturas do holandês Piet Mondrian (1872-1944), por exemplo, embora repletas de formas geométricas regulares - ele só se permitia trabalhar com linhas retas e planos quadrados ou retangulares - são, na opinião de Fayga, verdadeiras obras e não exercícios de geometria. Isso porque Mondrian atribui a elas dupla função (Ostrower, 1998, p. 91). Em seus quadros, essas formas ora funcionam como 'figuras' autônomas ora como fundo. Essa ambivalência, segundo a artista, não existe na geometria.

\section{Uma questão em aberto}

Embora não considerasse as formas da natureza obras de arte, havia nelas um aspecto que instigava Fayga: Como era possível que sementes de girassol, cascas de caracol, colméias, estrelas do mar, conchas e vários outros elementos da natureza respeitassem a mesma proporção matemática ${ }^{8}$ utilizada por artistas na construção do Epidaurus e na pintura da Mona Lisa? A matemática era capaz de apreender um problema típico e constitutivo da natureza ou, ao contrário, era uma espécie de lente criada pelo homem que tornava transparente uma coisa da qual só se podia enxergar o exterior.

Luiz Alberto Oliveira lembra longos momentos compartilhados com a artista refletindo sobre o assunto. "Nunca esqueci momentos de silêncio depois de tocar problemas tão profundos e difíceis como esse", afirma. $^{9}$

Embora nunca tenha conseguido solucionar esse enigma - e esta é apenas uma das questões que deixou em aberto -, Fayga acreditava que o fato de a natureza utilizar a mesma regra para resolver seus problemas de crescimento e expansão que o artista usava para resolver seus problemas de representação do mundo era uma insígnia da criatividade.

\section{Considerações finais}

Nas entrevistas realizadas, nos artigos lidos e no material pesquisado para a elaboração deste texto sobre Fayga Ostrower, foram inúmeras vezes ressaltadas a generosidade, sensibilidade, força e sabedoria da artista e pensadora.

Dona de uma personalidade marcante, Fayga teve papel fundamental no campo da arte e no pensamento intelectual brasileiro. Ela se destacou ainda como uma importante pensadora sobre arte e ciência no país. $\mathrm{O}$ fato de a história da arte e a história da ciência convergirem em vários períodos era, para Fayga, uma questão lógica, já que ambas as visões compartilham sempre a mesma realidade cultural. Qualquer ruptura nessa esfera haveria de ter conseqüências tanto na arte como na ciência. No entanto, ela se 
empenhou em compreender a reação de cada uma delas às transformações culturais e em entender em que pontos o pensamento artístico e o pensamento científico convergiam e em que pontos divergiam.

Certamente existem excelentes artistas que jamais pararam para refletir sobre as demais atividades humanas, e não há dúvida de que há renomados cientistas que não possuem o menor interesse pelo pensamento artístico-cultural. No entanto, é fundamental haver pessoas como Fayga, capazes de transitar pelos diversos campos do conhecimento humano e tornar esse diálogo mutuamente estimulante.

\section{REFERÊNCIAS BIBLIOGRÁFICAS}

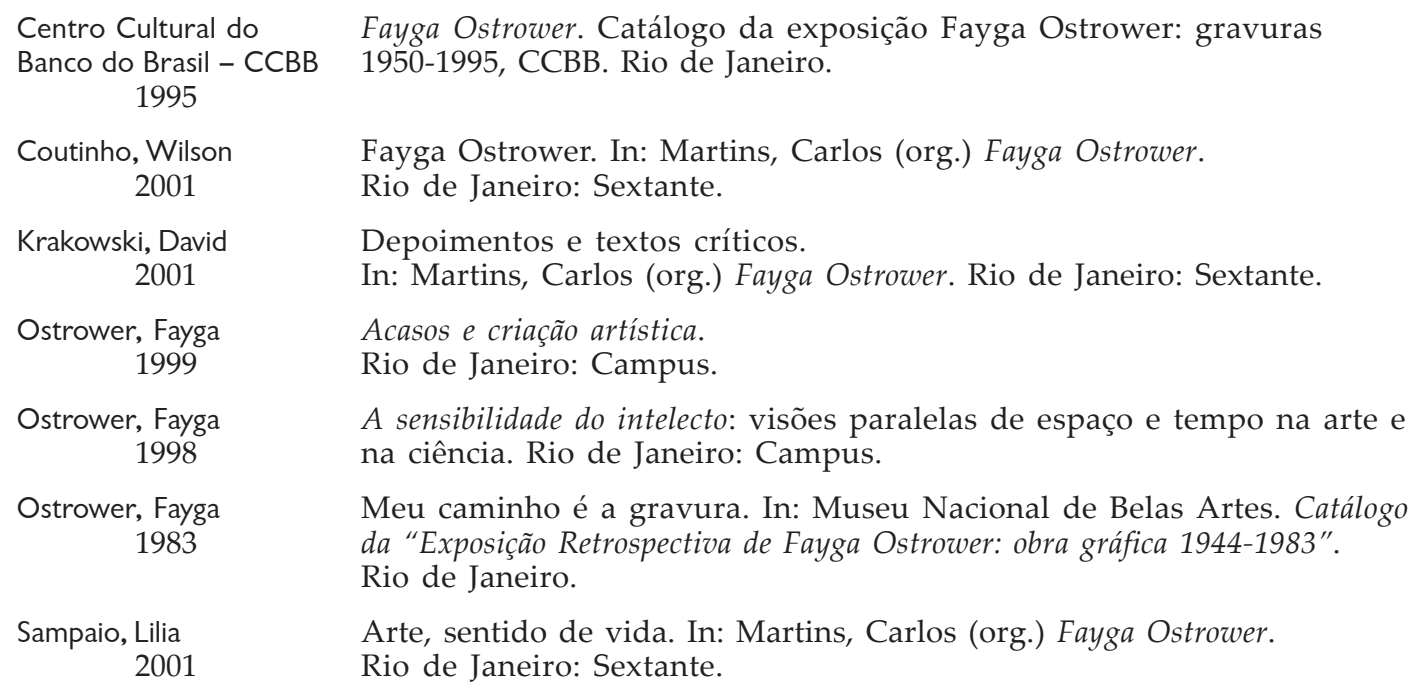

Recebido para publicação em julho de 2006. Aprovado para publicação em agosto de 2006.

O Instituto Fayga Ostrower: O acervo do Instituto Fayga Ostrower, criado em 2002, guarda obras que cobrem todos os períodos da produção artística de Fayga, sua biblioteca, objetos de trabalho, uma vasta e variada documentação (artigos, correspondências, fotos, jornais e vídeos), e encontra-se atualmente em fase de identificação e catalogação. Para conhecer mais, visite www.faygaostrower.org.br 


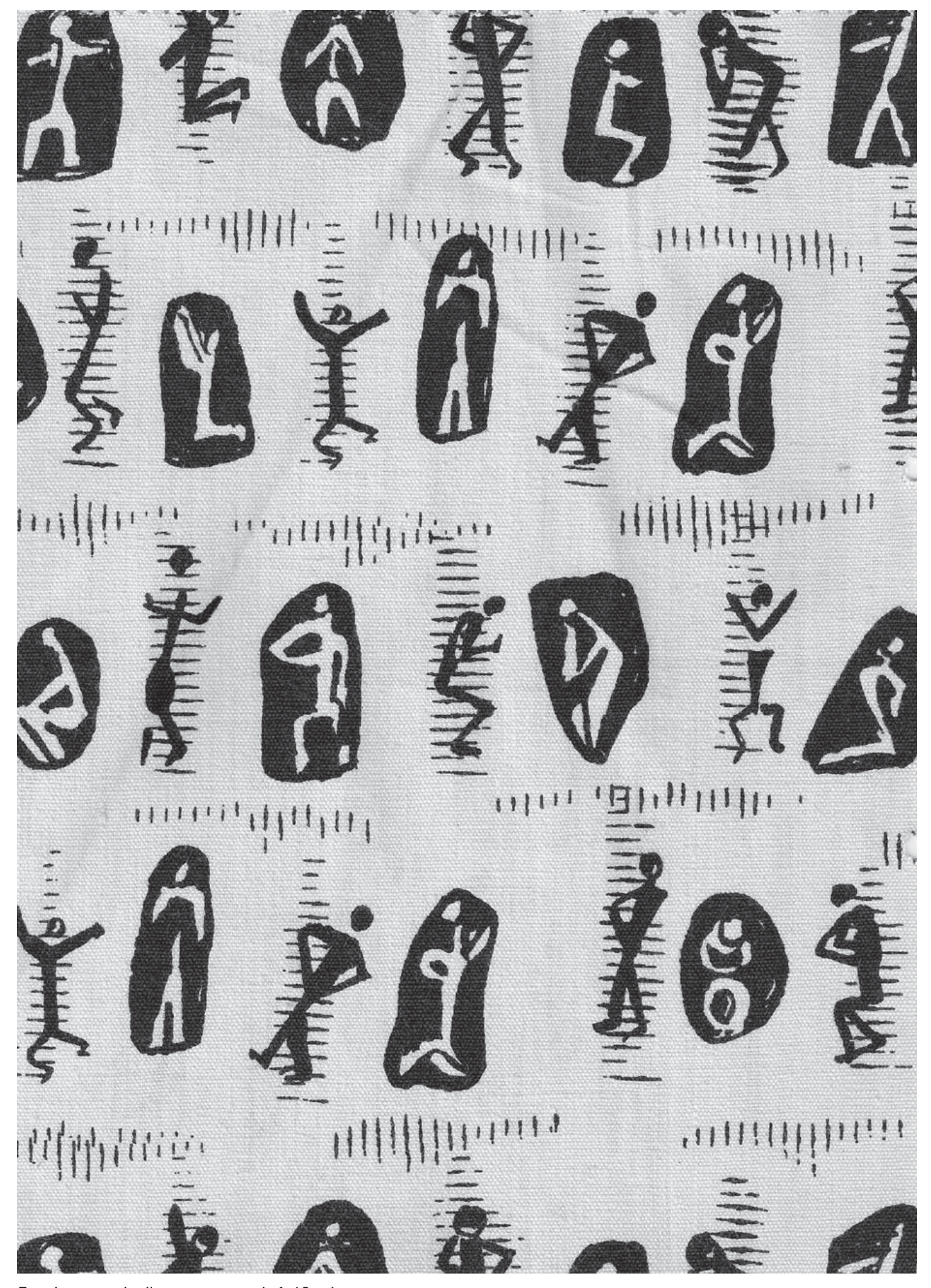

Fetiches, tecido (largura original: 1,40 m). 